\title{
Effect of Coarse Aggregate Sizes and Replacement Levels on the Strength of Palm Kernel Shell (PKS) Concrete
}

\author{
Olusola, K.O. ${ }^{1}$ and Babafemi, A.J. ${ }^{1}$
}

\begin{abstract}
The maximum coarse aggregate size used in concrete can impact on its strength. An investigation of the effect of coarse aggregate size and replacement level of granite with palm kernel shell (PKS) on the compressive and tensile strengths of PKS concrete were investigated. Mix proportion by weight of 1:1 $1 \frac{2}{2}: 2$ with w/c of 0.50 were used. All samples were tested at 7 and up to 90 days. Results showed that both compressive and splitting tensile strengths increased with increase in aggregate sizes. Both strengths however decreased with increase in replacement levels of granite with PKS. Optimum replacement level of granite with PKS was 25\% with compressive and tensile strengths of $22.97 \mathrm{~N} / \mathrm{mm}^{2}$ and $1.89 \mathrm{~N} / \mathrm{mm}^{2}$ respectively at maximum coarse aggregate size of $20 \mathrm{~mm}$. However, at 50\% PKS content, which results in lightweight concrete, compressive strength was $18.13 \mathrm{~N} / \mathrm{mm}^{2}$ which is above the minimum value of $17 \mathrm{MPa}$ for lightweight concrete.
\end{abstract}

Keywords: Compressive strength, maximum aggregate size, palm kernel shell (PKS), PKS concrete, replacement level, splitting tensile strength.

\section{Introduction}

Palm kernel shells (PKS) are agricultural waste obtained during the processing of palm oil and is available in large quantities in the tropical regions of the world, especially in Africa, Asia, and America. In Nigeria, annual generation of PKS as reported by Ndoke [1] is about 1.5 million tons. A proposal for its use, particularly in regions where they are abundant, can enhance the realization of 'Affordable Housing for All' agenda of past Nigeria government [2]. Previous studies [3-14] have shown that PKS is suitable as granular filter for water treatment, coarse aggregate in plain, lightweight, and normal weight concretes, and as a road building material.

The impact of aggregates on various characteristics and properties of concrete is undoubtedly considerable as they occupy 70-80 per cent of the volume of concrete [15]. Most of the works reported on PKS concrete have been carried out using a maximum aggregate size of $12.5 \mathrm{~mm}$ or $15 \mathrm{~mm}$. PKS are angular, flaky, parabolic and usually have smooth concave and convex surfaces while their thicknesses do vary from $1.2 \mathrm{~mm}$ to $3.0 \mathrm{~mm}$.

\footnotetext{
${ }^{1}$ Obafemi Awolowo University, Пle-Ife, Osun State, NIGERIA Email: dewunmi2001@yahoo.com
}

Note: Discussion is expected before June, $1^{\text {st }} 2013$, and will be published in the "Civil Engineering Dimension" volume 15, number 2, September 2013.

Received 20 September 2012; revised 18 December 2012; accepted 14 February 2013
Many of these recent research investigations have addressed the compressive, flexural and tensile splitting strengths, modulus of elasticity, modulus of rupture, pullout bond strength, drying shrinkage, initial surface absorption, durability performance, water permeability, and water absorption capacity. However, data on the effects of maximum coarse aggregate sizes and replacement levels of granite with PKS on these engineering properties of palm kernel shell concrete are scarce in literature. Alengaram [16] considered the effect of aggregate size and aggregate size proportion on the strength properties of PKS concrete. However, their work never considered the proportion of replacement of granite with PKS in PKS concrete as done in this research.

It had been reported by Abang [17] that higher proportions of the shell in a mix lower the workability and compressive strength of PKS concrete. The strength of the shell also plays a significant role in the strength of the concrete [14]. Mahmud [18] reported the poor bond between PKS aggregate and the matrix as a result of the smooth and convex nature of the shell producing a poorly compacted concrete. However, higher sand content has been reported to improve significantly the bond strength of PKS concrete [18, 19].

The focus of this study therefore is to investigate the impact of varying maximum coarse aggregate sizes and replacement levels of granite with PKS on the compressive and splitting tensile strength of PKS concrete with high sand content. 


\section{Materials and Methods}

The basic components of PKS concrete are cement, sand, granite and/or PKS. The fine aggregate, sharp (angular) sand, had a specific gravity and fineness modulus of 2.55 and 3.12, respectively. The PKS obtained from a local mill along Ede road in Ile-Ife, Nigeria, was already in the cracked form. The fibrous outer parts of the nut already removed. The shells were kept outdoors under a shed for three months. This enabled the oil coating to be removed by natural weathering which is one of the methods recommended for pre-treatment [20-23] among others. The PKS were later washed and sun-dried before use. The granite used was purchased in lleIfe, Nigeria. The coarse aggregates, PKS and granite, were graded into three maximum coarse aggregate sizes, passing through $10 \mathrm{~mm}, 14 \mathrm{~mm}$, and $20 \mathrm{~mm}$ but retained on $5 \mathrm{~mm}$ BS sieve. The three maximum coarse aggregate sizes of PKS used were obtained from a stockpile of hand-cracked PKS. The cement used was obtained from the open market in lle-Ife and was that produced by the West African Portland Cement Company (WAPCO) that conforms to the requirements of BS EN 197-1 [24] for Ordinary Portland Cement.

A mix proportion by mass of $1: 1 \frac{1}{2}: 2$ was used for this work with a water/cement ratio of 0.50 . PKS was used to replace granite in steps of $25 \%$ from $0-100 \%$ in the mix to study the effect of proportions, while the three maximum coarse aggregate sizes were used to study its influence on PKS concrete. Steel moulds were used for casting test samples. The inner parts of the moulds were coated with used engine oil to ensure easy demoulding and smooth surface finish. Immediately after mixing, the wet mixture was cast into the moulds using hand trowel. For compressive strength test, $100 \mathrm{~mm}$ cube moulds used were filled in two layers, while for tensile splitting test, the cylindrical moulds of size $150 \times 300$ $\mathrm{mm}$ were filled in three layers. In both cases, each layer was compacted using the compaction rod (25 $\mathrm{mm}$ diameter steel rod). Each layer of the $100 \mathrm{~mm}$ cube and cylindrical specimens were compacted manually by uniformly distributing 25 strokes of the steel rod across the cross-section of the mould. The top of each mould was smoothened and levelled and the outside surfaces cleaned. The moulds and their contents were kept in the curing room at temperature of $23 \pm 1^{\circ} \mathrm{C}$ and relative humidity not less than $70 \%$. The specimens were demoulded and cured by complete immersion in water until testing.

\section{Physical and Mechanical Test}

The physical properties: dry sieve analysis of aggregates used, moisture content, workability, water absorption capacity, and demoulded density were determined following standard laboratory procedures as outlined by BS standards. All specimens were cured for 7, 28, 56, and 90 days, brought out of the curing tank and allowed to rest for two hours and then crushed to determine the mechanical properties. Three replicates were made for specimens at each curing age. The average values of the maximum loads, at which each group of three specimens failed, was found and the compressive strength determined. This is in accordance with BS EN 12390-3 [25]. The tensile splitting strength was determined in accordance with BS EN 12390-5 [26]. Cylindrical specimens of 150 x $300 \mathrm{~mm}$ were used for this test. The cylindrical prisms were compressed along two diametrically opposed generators lying horizontal. To prevent multiple cracking and crushing at the point of loading, two thin plywood strips (25 mm thick) were placed between the loading platens and the specimen to distribute the load. The cylindrical prisms were hand-held in place to avoid tilting or rolling under load. The induced stress caused the specimen to fail by splitting into two halves across the loading plane.

\section{Results and Discussion}

\section{Dry Sieve Analysis of Aggregates Used}

The results of the dry sieve analysis revealed that sand, granite, and PKS have coefficients of uniformity of $7.2,1.77$, and 2.00 respectively. A coefficient of uniformity of 7.2 for sand, according to Vandevelde [27], showed that it was well graded, while granite and PKS were uniformly graded. These showed that the aggregates were suitable for making concrete, unlike a gap-graded or poorly graded aggregate having coefficient of uniformity less than 1.0.

\section{Moisture Content}

The measured moisture contents of granite, palm kernel shell, and sand were $0.22 \%, 1.20 \%$, and $8.88 \%$ respectively. Neville [28] posited that coarse aggregates rarely contains more than $1.0 \%$ of surface moisture but fine aggregate can contain in excess of $10 \%$. Since according to Neville [28], the moisture content of coarse aggregate is not significant on concrete mix, only the moisture content of sand was allowed for in the calculation of batched quantities.

\section{Workability}

The results of the slump test indicating the workability of the concrete for different percentage replacement of palm kernel shell with granite are shown in Table 1. The table indicates that the concrete slump decreases as the percentage of the palm kernel shell increased in the mixes. In the three different maximum aggregate-size mixes, the slump test values show concrete of workabilities ranging from very low to medium (35-75 $\mathrm{mm}$ ) according to Neville [28]. At 0\% PKS replacement 
level (normal concrete), results show collapsed slump for the three maximum aggregate-size mixes. This could be traced to the high water-cement ratio of 0.5 for a mix proportion by mass of $1: 1 \frac{1}{2}: 2$ used throughout the experimentation, so as to establish a basis of strength comparison between the PKS concrete and normal concrete. With $25 \%$ and $50 \%$ PKS; and 25\% PKS in the mixes with maximum aggregate sizes of $10 \mathrm{~mm}$ and $20 \mathrm{~mm}$ respectively, medium workabilities were achieved while low workabilities were obtained for the remaining $25 \%$ and 50\% PKS mixes. However, for $75 \%$ and $100 \%$ PKS in the three mixes, slump were almost zero showing a stiff consistency. This revealed that to obtain high workability from PKS concrete, a waterreducing agent such as super plasticizer would have to be used as attested to by earlier researchers [10$12,18,29]$.

Table 1. Slump Values in (mm)

\begin{tabular}{cccc}
\hline \% PKS/Size & $10 \mathrm{~mm}$ & $14 \mathrm{~mm}$ & $20 \mathrm{~mm}$ \\
\hline 0 & Collapsed & Collapsed & Collapsed \\
25 & 30 & 22 & 40 \\
50 & 40 & 18 & 12 \\
75 & 2 & 4 & 1 \\
100 & 0.5 & 3 & 0 \\
\hline
\end{tabular}

\section{Water Absorption Capacity}

The water absorption capacity of the PKS was $9.03 \%$. This result is within the range of absorption capacity of lightweight aggregates which has been put at 5-20\% [30]. Table 2 shows the details of some of the physical properties of the aggregates used.

Table 2. Properties of PKS, Granite and Sand

\begin{tabular}{lccl}
\hline Properties & PKS & Granite & Sand \\
\hline Maximum size (mm) & 20 & 20 & 5 \\
Specific gravity & 1.58 & 2.6 & 2.55 \\
Water absorption for $24 \mathrm{~h}(\%)$ & 9.03 & 3.85 & 3.75 \\
\hline
\end{tabular}

\section{Demoulded Density}

The results of the demoulded density of the $100 \mathrm{~mm}$ cubes, of the different maximum aggregate-size mixes are shown in Table 3 . The results show that at $0 \%$ and $25 \%$ PKS replacement levels, the demoulded density of PKS concrete ranges between 2000 and $2400 \mathrm{~kg} / \mathrm{m}^{3}$, classifying them as dense concrete [28]. At $50 \%, 75 \%$ and $100 \%$ PKS replacement levels, the demoulded density of PKS concrete ranges between 1900 and $1350 \mathrm{~kg} / \mathrm{m}^{3}$, this makes them lightweight $[10,15,31]$. It can, however, be seen from Table 3 that the density is a function of the level of replacement of granite with palm kernel shell. The density decreases as the percentage of palm kernel shell increases in the mix. This could be attributed to the fact that palm kernel shell has a lower relative density when compared with granite. It also increases with aggregate size.
Table 3. Demoulded Densities of PKS Concrete in $\mathrm{kg} / \mathrm{m}^{3}$

\begin{tabular}{cccc}
\hline \multirow{2}{*}{$\%$ PKS } & \multicolumn{3}{c}{ Maximum Aggregate Sizes $(\mathrm{mm})$} \\
\cline { 2 - 4 } & 10 & 14 & 20 \\
\hline 0 & 2325 & 2350 & 2400 \\
25 & 2025 & 2040 & 2060 \\
50 & 1840 & 1860 & 1900 \\
75 & 1435 & 1460 & 1500 \\
100 & 1350 & 1380 & 1400 \\
\hline
\end{tabular}

\section{Compressive Strength}

Figures 1 to 4 show that the compressive strength increases with curing age from 7 to 90 days for all sizes of the maximum coarse aggregates like normal concrete. Neville [28] posited that the knowledge of the strength-time relation is of importance when a structure is to be put into use and subjected to full loading, at a later age. The rate of increase of the compressive strength decreases as the curing age increases. For example, for maximum aggregate sizes of $10 \mathrm{~mm}, 14 \mathrm{~mm}$, and $20 \mathrm{~mm}$ at $50 \%$ PKS content, the percentage increase in strength between the consecutive curing ages were $34.45 \%$, $14.02 \%, 7.93 \%$; 34.25\%, 15.93\%, 3.22\%; and 32.05\%, $24.66 \%, 16.95 \%$ respectively.

Similarly, for maximum aggregate sizes of $10 \mathrm{~mm}$, $14 \mathrm{~mm}$ and $20 \mathrm{~mm}$ at $100 \%$ PKS content, the corresponding percentage increases in strength between consecutive curing ages were, respectively, $17.63 \%, 24.84 \%, 17.86 \%$; 38.76\%, 9.85\%, 2.68\%; and $38.78 \%, 2.59 \%, 2.52 \%$. This trend appeared to be similar, irrespective of the maximum aggregate size except some slight variations as in the case of $100 \%$ PKS content for $10 \mathrm{~mm}$ maximum aggregate size. These results indicate that compressive strength increases progressively with the increase in the maximum coarse aggregate sizes, with $20 \mathrm{~mm}$ giving the highest strength of $27.93 \mathrm{~N} / \mathrm{mm}^{2}$ for 28 days curing at $25 \%$ PKS content in the mix. The compressive strength decreases with increase in the PKS content in the mix at an increasing rate, irrespective of the curing age and the aggregate size (Figures 1-4). As the replacement level of granite with PKS increased from 0 to $100 \%$, the lower the density of PKS concrete and the lower the compressive strength.

It should, however, be noted that at 50\% PKS content for $20 \mathrm{~mm}$ maximum coarse aggregate size, compressive strength obtained was $18.13 \mathrm{~N} / \mathrm{mm}^{2}$ at 28 days, which is more than the minimum of 17 $\mathrm{N} / \mathrm{mm}^{2}$ required for light weight concrete. At 90 days curing, there was still an increase of $19.65 \%$ in the compressive strength of PKS concrete after 28 days for $20 \mathrm{~mm}$ aggregate size concrete. The performance of $20 \mathrm{~mm}$ maximum aggregate size concrete can be attributed to the strength of the larger sized shells, and to the fact that the smaller sized shells packed the voids and ultimately influenced the strength by giving a more compact concrete. 


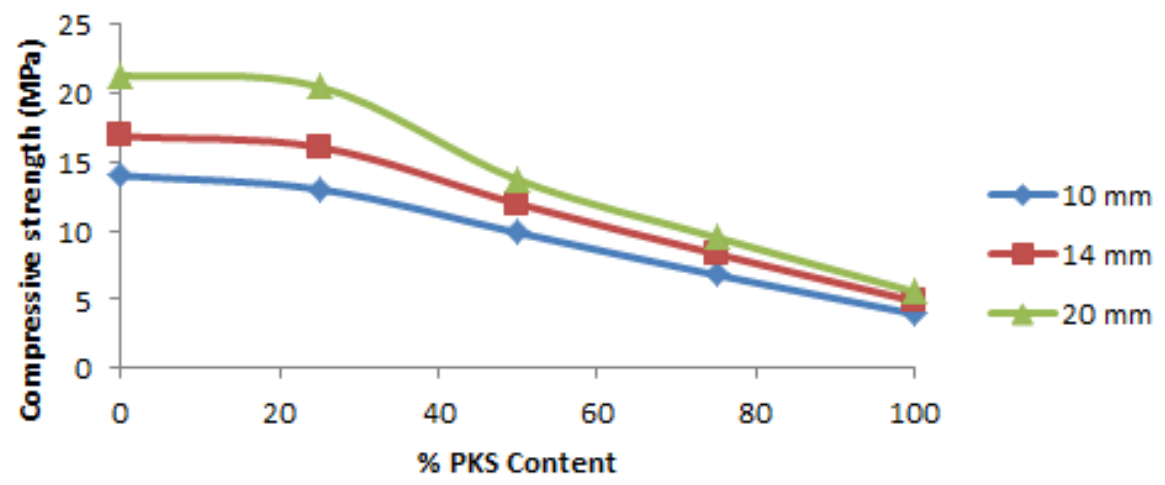

Figure 1. Compressive Strength of Concrete having Different \% PKS Content Cured for 7 Days

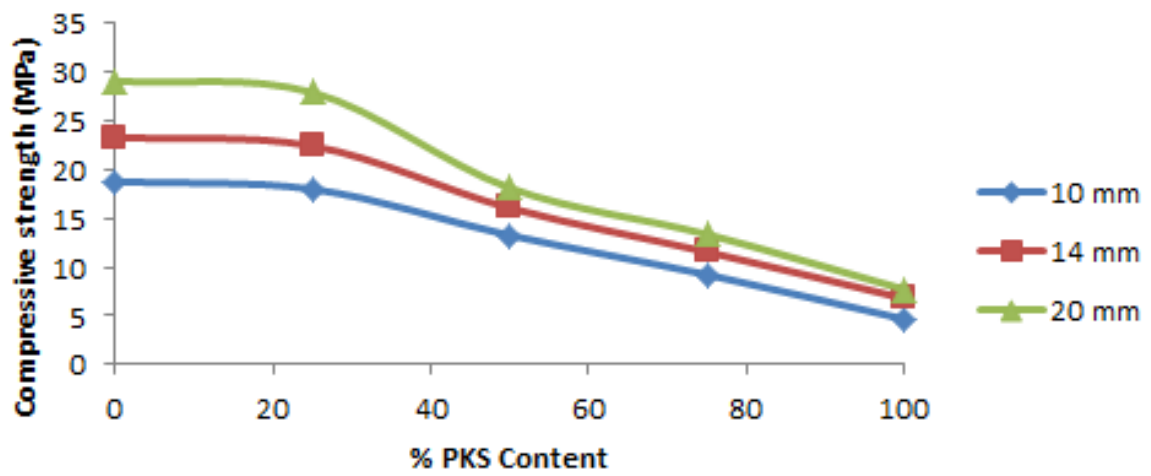

Figure 2. Compressive Strength of Concrete having Different \% PKS Content Cured for 28 Days

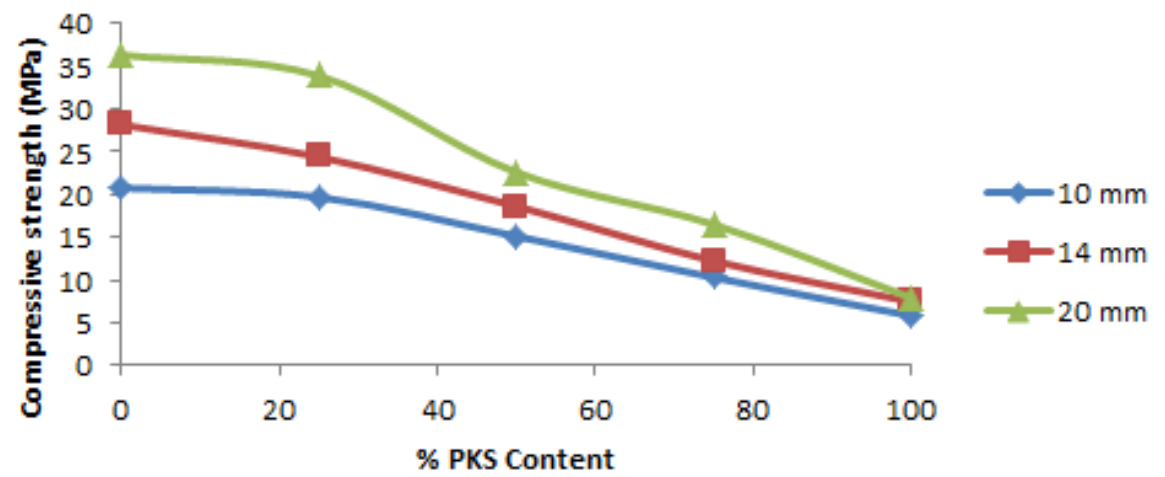

Figure 3. Compressive Strength of Concrete having Different \% PKS Content Cured for 56 Days

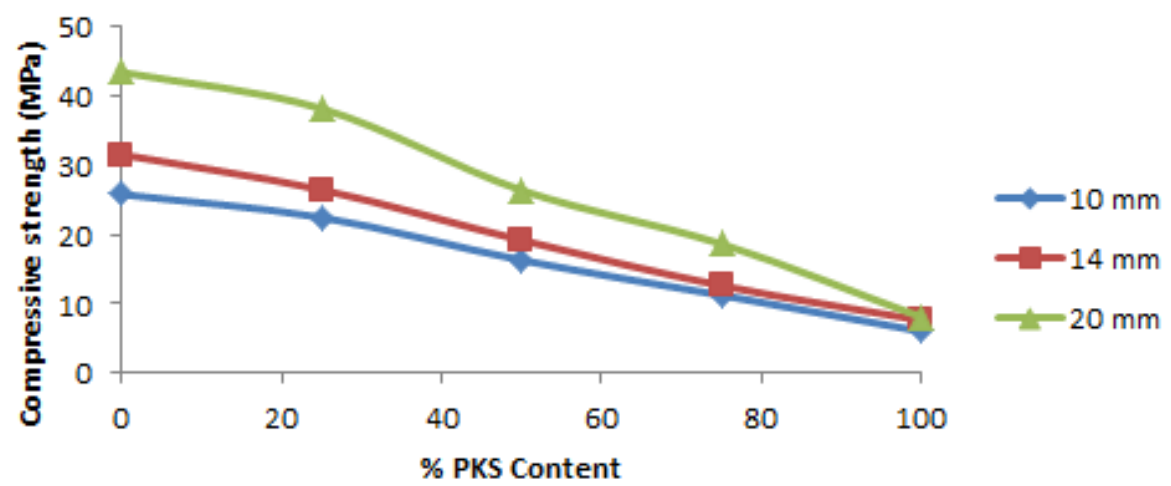

Figure 4. Compressive Strength of Concrete having Different \% PKS Content Cured for 90 Days 


\section{Tensile Strength}

The test results of the tensile strength are somewhat similar to the compressive strength test results. Figures 5 to 8 present the effect of maximum aggregate size and percent replacement at $7,28,56$, and 90 days curing on the tensile splitting strength of PKS concrete. A look at the figures show that the tensile splitting strength of PKS concrete increases with curing age; increases with maximum aggregate size; and decreases with increase in the percentage replacement of granite with PKS. While the increase in the mean tensile splitting strength was pronounced between 7 to 28 days, the increase in strength from the $56^{\text {th }}$ to the $90^{\text {th }}$ day was not significantly different for all the aggregate sizes. Maximum mean tensile splitting strengths were obtained from aggregate size of $20 \mathrm{~mm}$ at curing age of 90 days. An increase of $35.35 \%$ and $43.94 \%$ respectively in the tensile strength was observed for the $28^{\text {th }}$ day strength when the aggregate size changed from $10 \mathrm{~mm}$ to $14 \mathrm{~mm}$ and $10 \mathrm{~mm}$ to 20 $\mathrm{mm}$ for the control concrete (0\% PKS). Similar pattern was observed for $100 \%$ PKS in the concrete mix with $42 \%$ and $48 \%$ increases for same aggregate size.

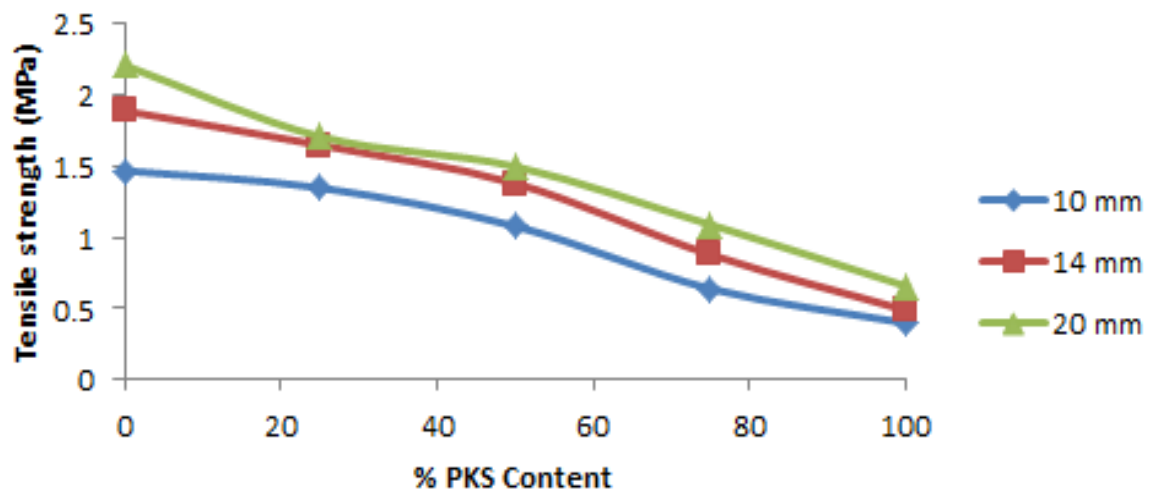

Figure 5. Tensile Strength of Concrete having Different \% PKS Content and Cured for 7 Days

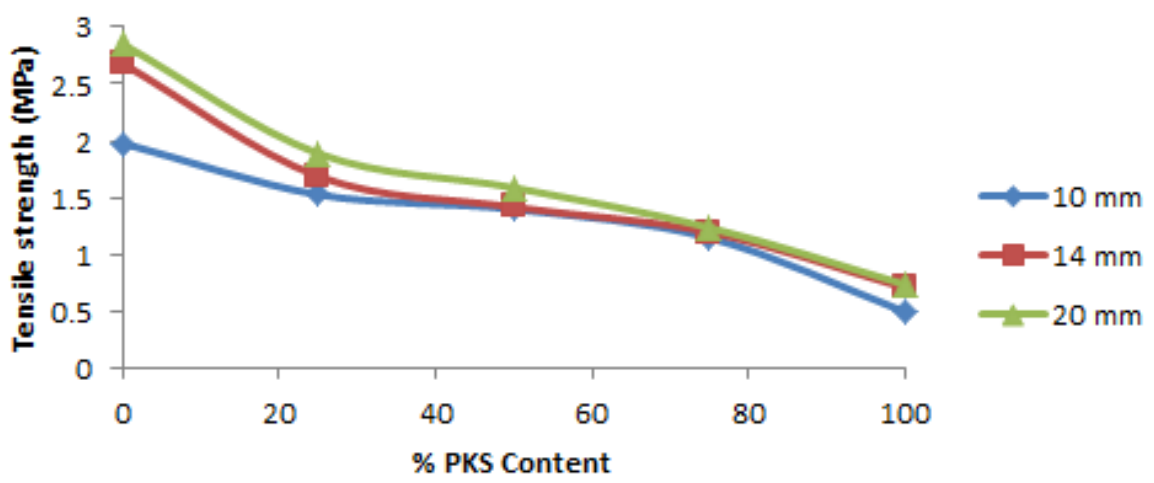

Figure 6. Tensile Strength of Concrete having Different \% PKS Content and Cured for 28 Days

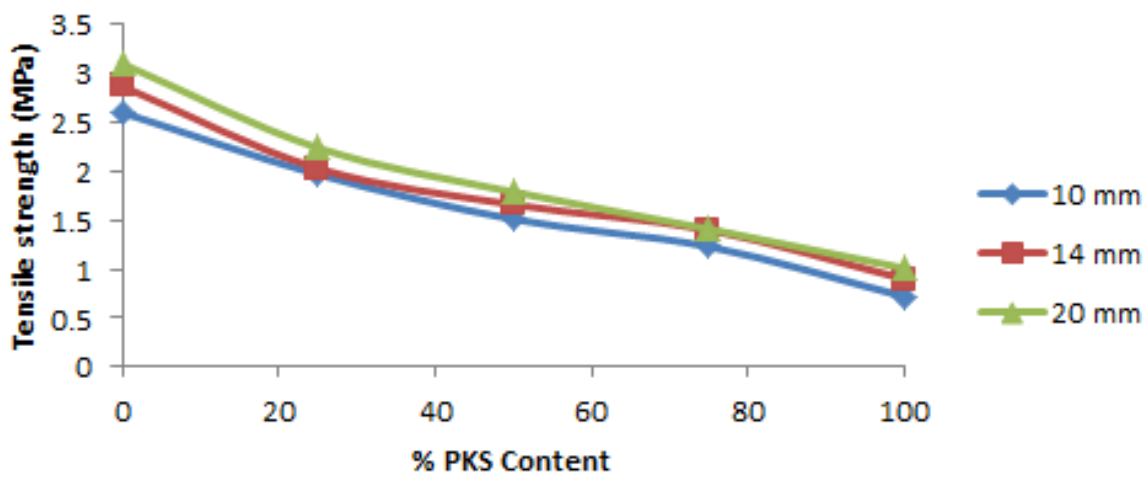

Figure 7. Tensile Strength of Concrete having Different \% PKS Content and Cured for 56 Days 


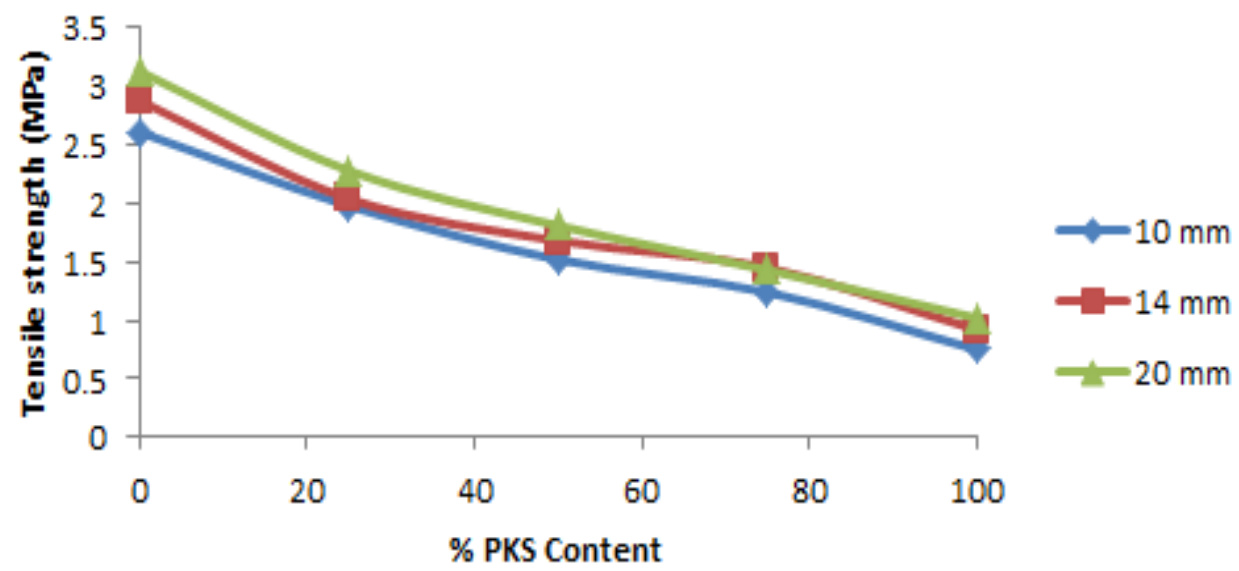

Figure 8. Tensile Strength of Concrete having Different \% PKS Content and Cured for 90 Days

\section{Statistical Analyses of Results}

The influence of aggregate size, percentage replacement of granite with PKS and curing age (called independent variables) on the compressive strength (called dependent variable) was statistically analyzed using Statistical Analysis Software [32]. The output of the Analysis of Variance (ANOVA) of the compressive strength test is presented in Table 4.

The analysis was aimed at determining which of the factors considered had significant effect on the compressive strength of the concrete. The results of the statistical analysis as shown in Table 4, indicated that the independent factors, and their interactions had significant effects on the compressive strength of the concrete at $95 \%$ confidence level $(\alpha=0.05)$.

This indicates that whenever any of the factors is varied, the compressive strength of the concrete changes and the degree of the variation is proportional to the magnitude of the change. The coefficient of determination (adjusted R-Square value) obtained from the analysis was 0.9969 (99.7\%). This implies a strong statistical association among the three independent variables and the dependent variable. The independent variables were estimated to account for $99.7 \%$ of the variance in the compressive strength of the concrete. The coefficient of correlation (square root of adjusted R-square) was obtained as $R=0.998$. This showed that a very strong correlation or linear relationship exist between the two sets of variables being considered. A strong correlation is assumed to exist between two variables if $0.5<R<1.0$, otherwise the correlation is weak.

The output of the statistical analysis of the ANOVA for the tensile strength test shown in Table 5 revealed that the independent variables; aggregate size, curing age, and replacement level of granite with PKS, each has a significant effect on the tensile splitting strength of PKS concrete. It is also shown that the factor interactions also have significant effect on the tensile splitting strength. The coefficient of determination (adjusted R-Square value) obtained from the analysis was $0.9992(99.9 \%)$. This implies a strong statistical association among the three independent variables and the dependent variation. The independent variables were estimated to account for $99.9 \%$ of the variance in the tensile strength of the concrete.

Table 4. ANOVA for Compressive Strength Test

\begin{tabular}{lrrrrc}
\hline Source & DF & Type III SS & Mean Square & F Value & Pr $>$ F \\
\hline Aggregate size & 2 & 618.841 & 309.421 & 6567.89 & $<0.000$ \\
Replacement (\%) & 4 & 6480.284 & 1620.071 & 34388.30 & $<0.000$ \\
Aggregate size Replacement (\%) & 8 & 74.723 & 9.340 & 198.26 & $<0.000$ \\
Curing age & 3 & 1408.835 & 469.612 & 9968.17 & $<0.000$ \\
Aggregate size Curing age & 6 & 28.959 & 4.826 & 102.45 & $<0.000$ \\
Replacement Curing age & 12 & 245.423 & 20.452 & 434.12 & $<0.000$ \\
Aggregate size Replacement Curing & 24 & 31.250 & 1.302 & 27.64 & $<0.000$ \\
Error & 120 & 5.653 & 0.047 & & \\
\hline
\end{tabular}


Table 5. ANOVA for Tensile Strength Test

\begin{tabular}{lrrrrc}
\hline Source & DF & Type III SS & Mean Square & F value & Pr $>$ F \\
\hline Aggregate size & 2 & 3.411 & 1.706 & 1704.66 & $<0.000$ \\
Replacement (\%) & 4 & 66.499 & 16.625 & 16615.50 & $<0.000$ \\
Aggregate size Replacement (\%) & 8 & 0.889 & 0.111 & 111.04 & $<0.000$ \\
Curing age & 3 & 9.056 & 3.019 & 3017.04 & $<0.000$ \\
Aggregate size Curing age & 6 & 0.118 & 0.020 & 19.60 & $<0.000$ \\
Replacement Curing age & 12 & 1.813 & 0.151 & 150.98 & $<0.000$ \\
Aggregate size Replacement Curing & 24 & 0.489 & 0.020 & 20.38 & $<0.000$ \\
Error & 120 & 0.120 & 0.001 & & \\
\hline
\end{tabular}

\section{Conclusion}

Based on the experimental work considered in this research on PKS concrete containing three coarse aggregate size range and five different replacement levels of granite with PKS cured at four curing ages, the following can be concluded:

1) The slump values were highest at $25 \%$ PKS contents $(22-40 \mathrm{~mm})$ but reduced to zero at $100 \%$ PKS content.

2) Twenty millimeters maximum aggregate size has the highest demoulded density which also has the biggest effect on both the compressive and tensile strengths. At $25 \%$ PKS content in the mix, densities of specimens were dense-weight for all aggregate sizes. However, at 50-100\% PKS contents, densities of specimens were lightweight.

3) Compressive strength of PKS concrete increased with increase in aggregate sizes at all curing ages. Optimum strength at 28 days was obtained for $20 \mathrm{~mm}$ maximum aggregate size specimen at $25 \%$ PKS content. However, at 50\% PKS content, which is lightweight, compressive strength, was $18.13 \mathrm{~N} / \mathrm{mm}^{2}$ for $20 \mathrm{~mm}$ maximum aggregate size specimen, which is above the minimum value of $17 \mathrm{~N} / \mathrm{mm}^{2}$ for lightweight concrete.

4) The tensile splitting strength of PKS concrete also increased with increase in the maximum aggregate size, with $20 \mathrm{~mm}$ giving the highest strength value at 28 days curing. Replacement level of granite with PKS decreased the tensile strength with increase in the replacement level. As with the compressive strength, maximum tensile strength, $1.89 \mathrm{~N} / \mathrm{mm}^{2}$, was obtained at $25 \%$ PKS replacement.

5) Beyond 28 days, the compressive strength of PKS concrete is seen to significantly increase up to 90 days indicating that the PKS aggregate does not decay in the hardened state with age. However, the tensile increase in strength beyond 28 days is not significant.

6) The performance of the $20 \mathrm{~mm}$ maximum aggregate-sized concrete specimens can be attributed to the fact that the smaller sized shells packed the void created by the larger ones giving a more compact concrete.

\section{References}

1. Ndoke, P.N., Performance of Palm Kernel Shells as a Partial Replacement for Coarse Aggregate in Asphalt Concrete, Leonardo Electronic Journal of Practices and Technologies, 5(9), 2006, pp. 145152.

2. Olawuyi, B.J., Olusola, K.O., and Babafemi, A.J., Influence of Curing Age and Mix Composition on Compressive Strength of Volcanic Ash Blended Cement Laterized Concrete, Civil Engineering Dimension, 14(2), 2012, pp. 84-91.

3. Okafor, F.O., Palm Kernel Shell as a Lightweight Aggregate for Concrete, Cement and Concrete Research, 18(6), 1988, pp. 901-910.

4. Nuhu-Koko, M.K., The Use of Palm Kernel Shell as Aggregates for Concrete, The 21st Annual Conference of Materials Testing, Control and Research, Federal Ministry of Works, Lagos, Nigeria, 1990, pp. 20-23.

5. Olateju, O.T., The Efficacy of Light Weight Aggregate from Palm Kernel Shells, Journal of Housing Science, 15(4), 1992, pp. 263-276.

6. Falade, F., The Use of Palm Kernel Shell as Coarse Aggregate in Concrete, Journal of Housing Science, 16(3), 1992, pp. 213-219.

7. Omange, G.N., Palm Kernel Shells as Road Building Materials, Nigerian Society of Engineers Technical Transactions, 36(1), 2001.

8. Ayangade, J.A., Olusola, K.O., Ikpo, I.J., and Ata, O., Effect of Granite Dust on the Performance Characteristics of Kernelrazzo Floor Finish, Building and Environment, 39(10), 2004, pp. 1207-1212.

9. Mannan, M.A. and Ganapathy, C., Concrete from an Agricultural Waste-oil Palm Shell (OPS). Building and Environment, 39(4), 2004, pp. 441448.

10. Teo, D.C.L., Mannan, M.A., and Kurian, V.J., Behaviour of Reinforced Lightweight Concrete Beams Made with Oil Palm Shell, Journal of Advanced Concrete Technology, 4(3), 2006, pp. 1 10. 
11. Teo, D.C.L., Mannan M.A., and Kurian, V.J., Structural Concrete using Oil Palm Shell (OPS) as Lightweight Aggregate, Turkish Journal of Engineering and Environmental Sciences, 30, 2006, pp. 251-257.

12. Teo, D.C.L., Mannan, M.A., and Kurian, V.J., Structural Behaviour of Singly Reinforced OPS Beams, in: Proceedings of the $6^{\text {th }}$ Asia-Pacific Structural Engineering and Construction Conference (APSEC), 5-6 September, 2006, Kuala Lumpur, Malaysia.

13. Olanipekun, E.A., Olusola, K.O., and Ata, O., A Comparative Study of Concrete Properties using Coconut Shell and Palm Kernel Shell as Coarse Aggregate, Building and Environment, 41(3), 2006, pp. 297-301.

14. Raheem, A.A., Nwakanma, E.O., and Ogunleye, K.O., Engineering Properties of Palm Kernel Shell as Fine and Coarse Aggregates, USEP: Journal of Research Information in Engineering, 5(1), 2008, pp. 56-67.

15. Shetty, M.S., Concrete Technology: Theory and Practice, S.Chand and Company Ltd, Ram Nagar, New Delhi, 2002.

16. Alengaram, U.J., Jumaat M.Z., and Mahmud, $\mathrm{H}$., Influence of Cementitious Materials and Aggregate Content on Compressive Strength of Palm Kernel Shell Concrete, Journal of Applied Science, 8(18), 2008, pp. 3207-3213.

17. Abang, A.A.A., Utilisation of Agricultural Wastes as Aggregates for Low-cost Construction Materials, Proceedings of a Regional Seminar, Universiti Putra Malaysia, 15-17 September 1982, pp. 127-142.

18. Mahmud, H., Jumaat, M.Z., and Alengaram, U.J., Influence of Sand/cement Ratio on Mechanical Properties of Palm Kernel Shell Concrete. Journal of Applied Sciences, 2009, pp. 1764-1769.

19. Babafemi, A.J. and Olawuyi, B. J., Effect of Replacement of Sand with Granite Fines on the Compressive and Tensile Strengths of Palm Kernel Shell Concrete, Proceedings of the West Africa Built Environment Research (WABER) Conference, Accra, Ghana, 19-21 July, 2011, pp. 371-378.
20. Mindess, S., Young J.F., and Darwin, D., Concrete, $2^{\text {nd }}$ Edition, Prentice Hall, USA, 2003.

21. Salam, S.A., Lightweight Concrete Made from Palm Oil Shell Aggregates and Rice Husk. Proceedings of a Regional Seminar. Universiti Putra Malaysia, 1982, pp. 177-196.

22. Mohd Noor, M.J., Juosh, A., and Ghazali, A.H., Management and Utilisation of Oil Palm WastesA Review, Regional Information Centre on the Management and Utilization of Wastes, Universiti Putra Malaysia, 1990.

23. Okafor, F.O., Eze-Uzomaka, O.J., and Eguniwe, N., The Structural Properties and Optimum Mix Proportions of Palmnut Fibre-reinforced Mortar Composite. Cement and Concrete Research, 26(7), 1996, pp. 1045-1055.

24. BS EN 197-1, Cement-Composition, Specifications and Conformity Criteria for Common Cement, British Standards Institution, 2000.

25. BS EN 12390-3, Testing Hardened Concrete Part-3: Compressive Strength of Test Specimens, British Standards Institution, 2002.

26. BS EN 12390-5, Testing Hardened ConcretePart-5: Flexural Strength of Test Specimens, British Standards Institution, 2000.

27. Vandevelde, P.E., Structural Mechanics, GEM Engineering Inc., 2008.

28. Neville, A. M., Properties of Concrete, Addison Wesley, Longman Limited, England, 1995.

29. Teo, D.C.L., Mannan, M.A., and Kurian, V.J., Utilization of Solid Waste Oil Palm Shell (OPS) in Concrete Production, Proceedings of the International Conference on Natural Resources and Environmental Management, Kuching, Sarawak, Malaysia, 2005, pp. 135-140.

30. Portland Cement Association, Design and Control of Concrete Mixtures, Mlonios: Shokie, 1979.

31. Newman, J.B., Properties of Structural Lightweight Aggregate Concrete, Clarke JL, editor, Structural Lightweight Aggregate Concrete. Blackie Academic \& Professional, 2003, pp. 1944.

32. SAS, Statistical Analysis Software Guide for Personal Computers. Release 9.1. SAS Institute Inc., Cary, NC 27513, USA, 2002. 